
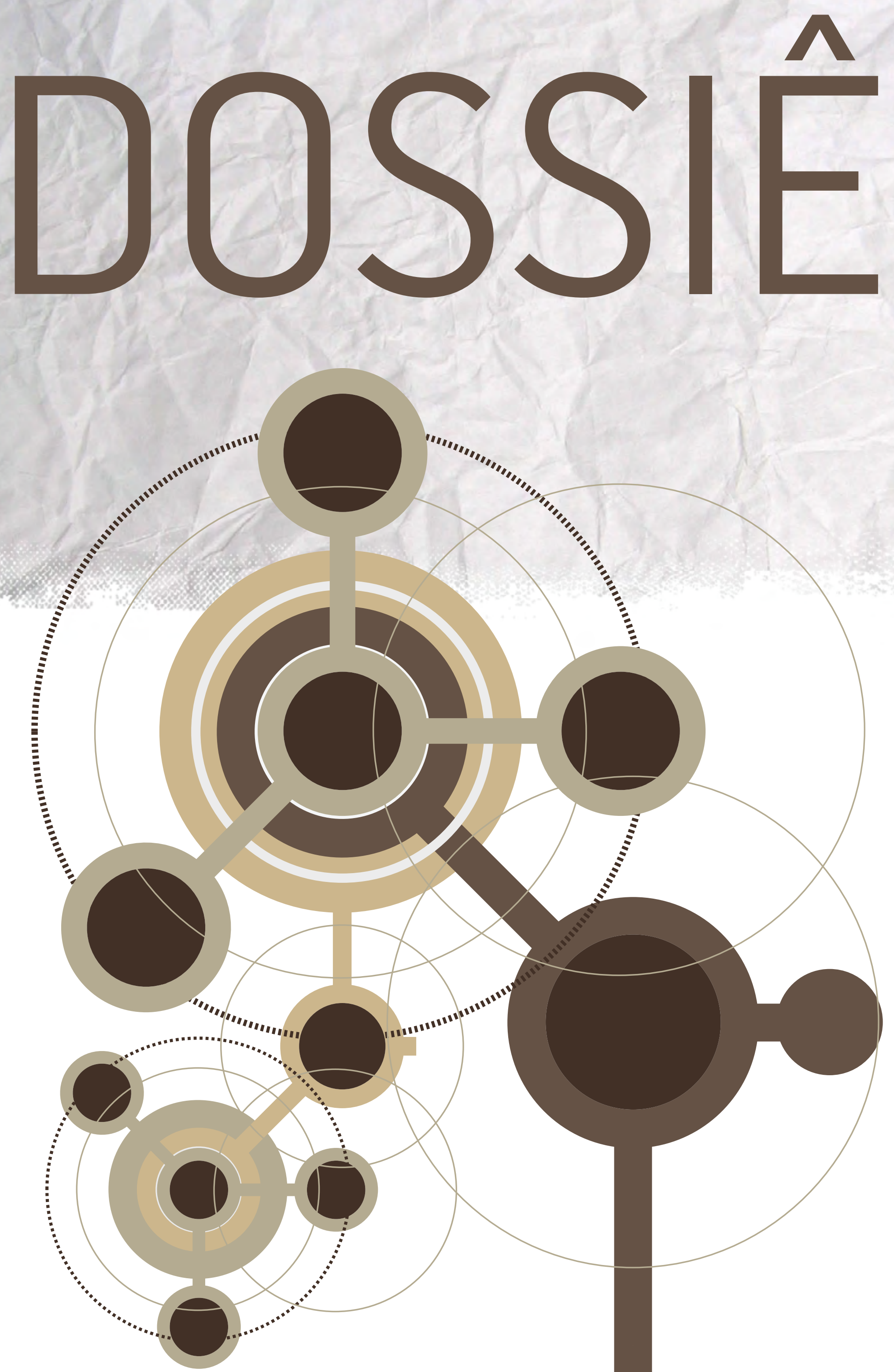


\section{Relacionamentos nas mídias sociais (ou relações públicas digitais): estamos falando da midiatização das relações públicas?}

Relationships in the social media (or digital public relations): are we talking about mediatization of public relations?

Relacionamientos en las redes sociales (o relaciones públicas digitales): ¿estamos hablando de la mediatización de las relaciones públicas?

\section{Carolina Frazon Terra}

- Doutora e mestre em Ciências da Comunicação pela Escola de Comunicações e Artes da Universidade de São Paulo (ECA-USP)

- $\quad$ Especialista em Gestão Estratégica em Comunicação Organizacional e Relações Públicas pela ECA-USP

- Graduada em Relações Públicas pela Universidade Estadual Paulista (Unesp-Bauru)

- Docente dos cursos de pós-graduação lato sensu de Gestão Estratégica em Comunicação Organizacional e Relações Públicas e Gestão da Comunicação Digital, da ECA-USP

- Docente da Pós-Graduação em Comunicação Digital na Fundação Armando Álvares Penteado (Faap)

- Publicou os livros Blogs corporativos: modismo ou tendência? e Mídias sociais... e agora?

- $\quad$ Edita os blogs Rpalavreando (http://rpalavreando.com.br) e Relações (http://www.blogrelacoes.com.br)

- $\quad$ E-mail: carolinaterra@gmail.com 


\section{Resumen}

Este artigo traz uma reflexão acerca do processo de midiatização dos relacionamentos, especificamente das relações entre as organizações e seus públicos, e de como todo esse cenário, atrelado à digitalização, afeta as relações públicas e 0 comportamento dos usuários nas redes sociais on-line. Também apresenta alguns casos reais de empresas se relacionando, através do ambiente digital, com a imprensa; com usuários de mídias sociais por meio de influenciadores on-linee por meio de temas ligados à responsabilidade socioambiental; e com consumidores/clientes, por meio de estratégias de SAC digital.

\section{PALABRAS CLAVES: RELAÇÕES PÚBLICAS • RELAÇÕES PÚBLICAS DIGITAIS • MIDIATIZAÇÃO• REDES SOCIAIS ON-LINE• MÍDIAS SOCIAIS}

\section{Abstract}

The article provides a reflection on the mediatization of relationships, more specifically the relations between organizations and their publics, and of how this entire scenario, which is entailed to digitalization, affects public relations and the behavior of the users of online social networks. It also presents some true cases of companies that relate by means of the digital environment with the press; with users of the social media by means of online opinion makers and by means of themes related to socio-environmental responsibility; and with consumers/customers, by means of digital Customer Service strategies.

\section{KEYWORDS: PUBLIC RELATIONS •DIGITAL PUBLIC RELATIONS • MEDIATIZATION・ONLINE SOCIAL NETWORKS・SOCIAL MEDIA.}

\section{Resumo}

El artículo reflexiona sobre el proceso de mediatización de los relacionamientos, específicamente de las relaciones entre las organizaciones y sus audiencias y cómo todo este escenario, vinculado a la digitalización, afecta las relaciones públicas y el comportamiento de los usuarios en las redes sociales on-line. También se presentan algunos casos reales de empresas se relacionando a través del entorno digital, sea con la prensa, con los usuarios de medios sociales a través de influenciadores on-line y de temas relacionados con la responsabilidad socio-ambiental; y con los consumidores/clientes, a través de estrategias digitales de servicios atendimiento al cliente. 
izem André Lemos e Pierre Lévy (2010, p. 22) que a cibercultura "modifica hábitos sociais, práticas de consumo cultural, ritmos de produção e distribuição de informação, criando novas relações no trabalho e no lazer, novas formas de sociabilidade e de comunicação social". Com base nesse conceito, é possível dizer que a cibercultura transformou a comunicação e, com isso, as relações públicas.

As relações públicas são, por via de regra, uma função estratégica que planeja, executa e avalia a comunicação de uma organização e seus relacionamentos com os mais diversos públicos. Até aí, nada de novo. Porém, em função das tecnologias digitais da comunicação e da informação, tais relacionamentos acabam, muitas vezes, por desembocar no ambiente digital, sobretudo nas redes sociais on-line.

Ainda nos baseando em Lemos e Lévy (2010, p. 22), entre as principais características da cibercultura temos a liberação do polo emissor e a conexão em redes telemáticas, o que, consequentemente, cria novas relações de poder e de diálogo entre uma organização e seus públicos. Isto, transportado para o universo das relações públicas, faz com que uma nova dinâmica de relacionamento, diálogo e interação se instaure entre uma organização e seus públicos de interesse. É o que chamamos de relações públicas digitais, sobre o que discorreremos mais adiante.

Este artigo pretende discutir a mudança nos relacionamentos organizacionais, bem como a sua midiatização no panorama de evolução das mídias sociais, especialmente aplicadas ao universo corporativo.

\section{A EVOLUÇÃO DOS CONCEITOS DE RELACIONAMENTO E RELAÇÕES PÚBLICAS}

Afirmar que os relacionamentos e os formatos de comunicação se alteraram em função das tecnologias digitais é corriqueiro e usual. Manuel Castells (2009) já preconizava no final dos anos 2000 que uma nova modalidade comunicativa estava surgindo: a mass self communication. Em uma tradução livre, "autocomunicação de massa" ou "comunicação interpessoal de massa".

Tal comunicação interpessoal de massa, segundo Castells (2009) tem potencial de atingir audiências massivas, globais, mas a produção de conteúdo é gerada de modo pessoal. De acordo com esse modelo, o autor afirma que a maioria dos internautas acredita que pode agir no mundo por sua força de vontade, utilizando os seus próprios meios, estando presente na internet e nos dispositivos móveis.

Assim, mais uma vez, assistimos a mudanças na forma como as pessoas estão se relacionando com as organizações, obrigando estas últimas a estarem efetivamente presentes nos meios digitais e a fazerem uso de linguagens e posturas condizentes com a informalidade e o imediatismo. A chave do sucesso na prática de relações públicas digitais não está apenas no entendimento e/ou na manipulação das tecnologias disponíveis, mas, sobretudo, em entender como o comportamento dos públicos avança, se modifica e adquire novas nuances e características em função delas.

Gisela Castro (2013, p. 5) afirma que, nesse regime em que as marcas estão presentes nas redes sociais, é fundamental que elas saibam detectar mensagens que as mencionem, assim como entendam sobre quais delas devem agir prontamente. 0 que não se pode negligenciar é que há uma necessidade irreversível de se entender o que pensam, de onde se expressam e 
em que medida influenciam audiências aqueles que falam sobre marcas, produtos, serviços e experiências. É o conteúdo gerado pelo consumidor tendo relevância para as organizações na criação de estratégias de comunicação com ele.

Luciana Carvalho e Eugênia Barichello (2013), por sua vez, comparam as estratégias publicitárias às de relações públicas, sugerindo que as primeiras estão se aproximando cada vez mais das segundas com fins de diálogo e interação com os consumidores para gerar "ambientes mais fluidos, abertos e participativos". As autoras ainda reforçam que as organizações têm desenvolvido técnicas de monitoramento e escuta (que chama de active listening, escuta ou ausculta ativa, em uma tradução literal) de necessidades, demandas, insights e manifestações dos consumidores. Há quem denomine tal atividade monitoramento nas mídias sociais. Ambas ainda argumentam que o processo de construção das estratégias comunicacionais passa pelo consumidor, por meio de um exercício colaborativo, participativo e que necessita de anuência, empatia, confiança e respaldo destes, os quais denomina prosumers - consumidores profissionais, em tradução literal. Elucidamos tal conceito de consumidores profissionais (aproximando-o do termo usuário-mídia) em nosso livro Mídias sociais...e agora? O que você precisa saber para implementar um projeto de mídias sociais (Terra, 2011, p. 68-69).

Ao enfatizar a participação do consumidor como parceiro e fã das organizações, Castro $(2013$, p. 9) reforça que "as redes sociais digitais se apresentam como ambientes propícios para gerar repercussão a partir de certas experiências - positivas ou negativas - ligadas às marcas, produtos ou serviços".

Dessa forma, o cenário de relacionamento que vem se formando entre as organizações e seus públicos nas redes sociais digitais reconfigura as relações públicas, transformando-as em uma área fundamental e imprescindível para corporações, marcas, produtos ou serviços que pretendem estar e se engajar no ambiente digital.

Além disso, nunca a comunicação organizacional esteve tão próxima do marketing. Por meio do uso estratégico das lógicas do entretenimento e das experiências motivadas pelas marcas, a comunicação corporativa, antes ligada apenas ao institucional, vem tentando transformar o consumidor em fã e, com isso, construir uma imagem e uma reputação digitais por meio de ações dialógicas, interativas e participativas que culminem em seu encantamento. 0 resultado: uma base de fãs enorme que legitime a presença das marcas nas redes sociais. Mas, há que se pensar em estratégias não apenas de visibilidade e/ou presença, mas também de relacionamento, interação, diálogo, escuta e retorno à base de fãs e usuários de mídias sociais. Aí é que entram as relações públicas digitais.

Em outra ocasião, definimos que as relações públicas 2.0 se caracterizavam "pela atividade de mediação e/ou interação por parte de organizações ou agências (consultorias etc) com seus públicos na rede, especialmente, no que diz respeito às expressões e manifestações desses nas mídias sociais" (Terra, 2010, p. 101).

Em entrevista à revista Bites (apud Terra, 2010, p. 101), Todd S. Defren atribuiu às mídias sociais a remodelação das técnicas e filosofias e o crescimento das interações diretas entre consumidores e transparência corporativa. Trata-se de uma realidade em que marcas, usuários e situações (sejam elas polêmicas, de crise ou de destaque - virais) geram um rastro digital nas redes, cabendo a nós, profissionais de relações públicas, a função de gerenciamento de tais imagens e percepções junto aos públicos de interesse das organizações.

Frente ao cenário de relacionamento das organizações com seus públicos e dos usuários para as corporações por meio das mídias sociais, acreditamos que estamos diante de uma midiatização das relações públicas, que explicaremos a seguir. 


\section{RELAÇÕES PÚBLICAS E MIDIATIZAÇÃO}

0 termo midiatização ganhou notoriedade a partir da década de 1980, quando os pesquisadores passaram a considerar a análise da presença das mídias nas práticas sociais e culturais dos indivíduos (Couldry; Hepp, 2013) e não apenas o estudo dos meios. Aliás, para Andreas Hepp (2014), a mídia se caracteriza pelos instrumentos de comunicação técnica que nós utilizamos com fins de ampliação da nossa capacidade de comunicação. Já Stig Hjarvard (2013) aponta que a midiatização busca perceber como cultura e sociedade estão permeadas pela mídia.

Os estudos de midiatização, por sua vez, contêm duas correntes principais: a perspectiva institucionalista e a social construtivista. A corrente institucionalista entende a mídia como uma instituição social independente com suas próprias regras. A midiatização, nesse caso, seria a adaptação de diferentes campos sociais (político e religioso, por exemplo) a tais regras (Furtado, 2014, p. 3). Na perspectiva social construtivista, segundo Furtado, "as ferramentas da mídia interferem e geram consequências na construção dos discursos e posicionamentos sociais e culturais da sociedade".

Hepp (2014, p. 47) diferencia ambas, afirmando que a perspectiva institucionalista estaria interessada na mídia tradicional de massa, enquanto a social construtivista, nas práticas de comunicação cotidianas, tais como a mídia digital e a comunicação pessoal.

É dentro da corrente social construtivista que acreditamos encontrar-se a midiatização das relações públicas, uma vez que, dada a importância do ambiente digital e de suas ferramentas para o usuário/consumidor/cliente/cidadão, os relacionamentos se alteraram e migraram, em boa parte, para o universo das redes sociais on-line.

Antônio Fausto Neto (2008, p. 93) entende que as tecnologias acabam por conformar as relações sociais e que as mídias perderam o lugar de auxílio e complemento para se constituírem como "referência engendradora no modo de ser da própria sociedade, e nos processos de interação entre as instituições e os atores sociais". E complementa:

A expansão da midiatização como um ambiente, com tecnologias elegendo novas formas de vida, com as interações sendo afetadas e /ou configuradas por novas estratégias e modos de organização, colocaria todos - produtores e consumidores - em uma mesma realidade, aquela de fluxos.

Não seria tal pensamento de Fausto Neto a consagração de que as relações públicas se fazem absolutamente presentes e necessárias? Estando produtores e consumidores em uma mesma realidade e com capacidade de expressão, interação e relação, não se fazem necessárias construções de canais de diálogo que unam ambos os entes? Pensamos que sim.

A nosso ver, em conjunção com a teoria da midiatização, temos a corrente que estuda a ecologia da mídia. A perspectiva ecológica da mídia tem sua origem para além da sua materialidade técnica, envolvendo ambientes culturais que, juntos, formam um ecossistema. As mídias têm efeitos intrínsecos em nossa percepção. As modificações em cada meio ou no ambiente interferem no conjunto e impactam também as partes que o compõem. 0 ecossistema midiático é composto pelos meios de comunicação e pelas relações que estabelecem entre si e com a sociedade (Carvalho; Barichello, 2013, p. 62).

Lucia Santaella (apud Carvalho; Barichello, 2013, p. 66) indica que entre a era hegemônica da televisão e o advento da cultura digital, tecnologias de uso individual, descentralizado e não-padronizado (tevê a cabo, videocassete, walkman, fotocopiadoras, videojogos e os primeiros computadores portáteis) instabilizaram a lógica vigente da cultura de massas, introduzindo a cultura 
das mídias. Essa era marca também o receptor que de passivo passa a ser usuário, "o que teria preparado para a chegada das tecnologias digitais em rede que configuraram, por meio de apropriações tecnossociais, a cultura digital em cibercultura".

0 ponto de encontro de ambas as teorias, a nosso ver, reside no fato de que tanto a midiatização quanto o ecossistema midiático encaram o usuário das redes como agente ativo, capaz de produzir conteúdos e informações, influenciar, afetar percepções de seus pares na rede e ainda contribuir para o sucesso ou insucesso de muitas marcas, produtos ou serviços. Chamamos tal personagem ativo das redes de usuário-mídia (Terra, 2011, p. 67-68). Porém, o objeto de nossa análise neste artigo se concentra na atividade das relações públicas e em sua midiatização e não na figura do influenciador on-line ou usuário-mídia.

Defendemos, aqui, que as relações públicas estão se midiatizando, sobretudo no que tange à sua atividade no ambiente digital, pois acreditamos que, assim como Hjarvard (2012, p. 68), "sempre que os meios de comunicação, a partir disso, passam a funcionar como uma interface necessária para o desempenho de tal atividade social, estamos lidando com uma forma forte de midiatização".

As marcas, assim, se valendo do relacionamento por meio do ambiente digital, acabam por depender dele, muitas vezes, para se legitimarem e conseguirem interações, participações e colaborações. Para ilustrar o quanto 0 ambiente digital, sobretudo das redes sociais digitais, está presente nas estratégias de relações públicas das organizações, selecionamos, alguns exemplos reais que veremos a seguir.

\section{AS RELAÇÕES PÚBLICAS DIGITAIS MIDIATIZADAS NA PRÁTICA}

Consideramos que as relações públicas tratam da administração dos relacionamentos entre uma organização e seus mais diversos públicos de interesse. Assim, separamos alguns casos de empresas que têm programas de relacionamento digital com determinados segmentos de públicos por categorias. Vamos a eles.

\section{Relacionamento com a imprensa}

Para relacionar-se com a imprensa, as operadoras de telefonia Tim e Vivo criaram aplicativos digitais móveis que facilitam o contato dos jornalistas e influenciadores com as informações de ambas as empresas.

Figura 1-Exemplos de telas dos aplicativos das operadoras TIM e Vivo destinados à imprensa.
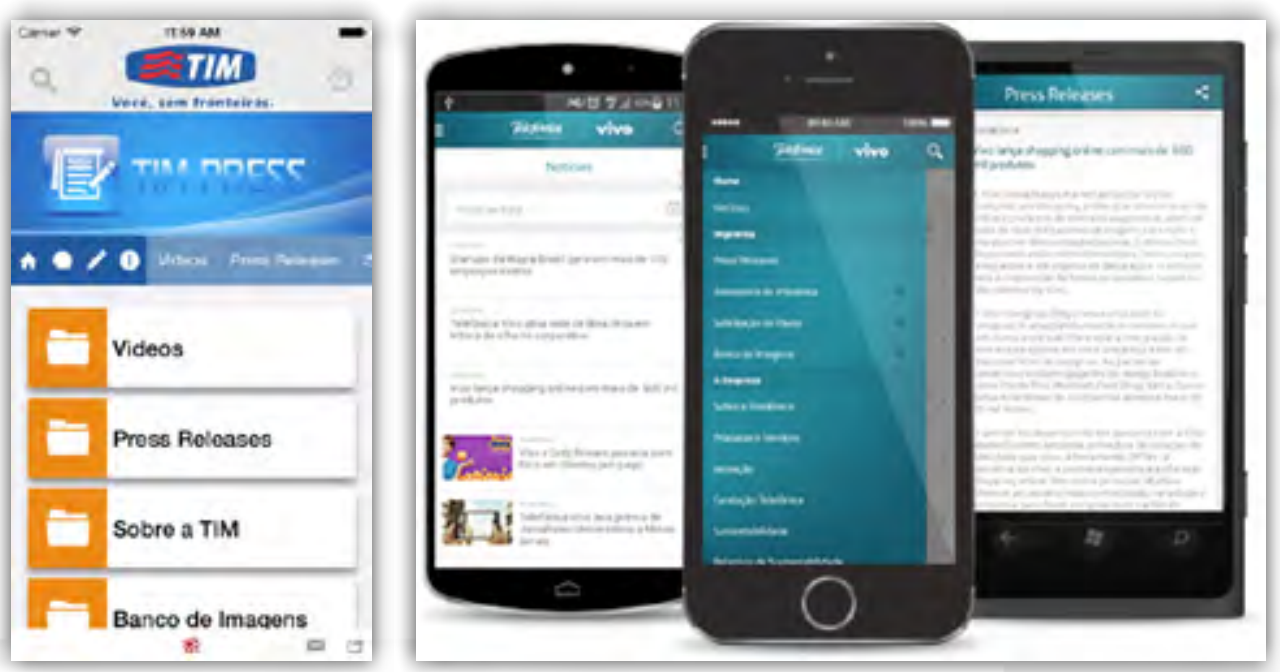
Outra empresa que também dedicou um formato digital ao público de formadores de opinião on-line foi a IBM, por meio do blog "TI + simples"', conforme imagem abaixo.

Figura 2-Blog $\mathrm{TI}+$ simples da IBM.

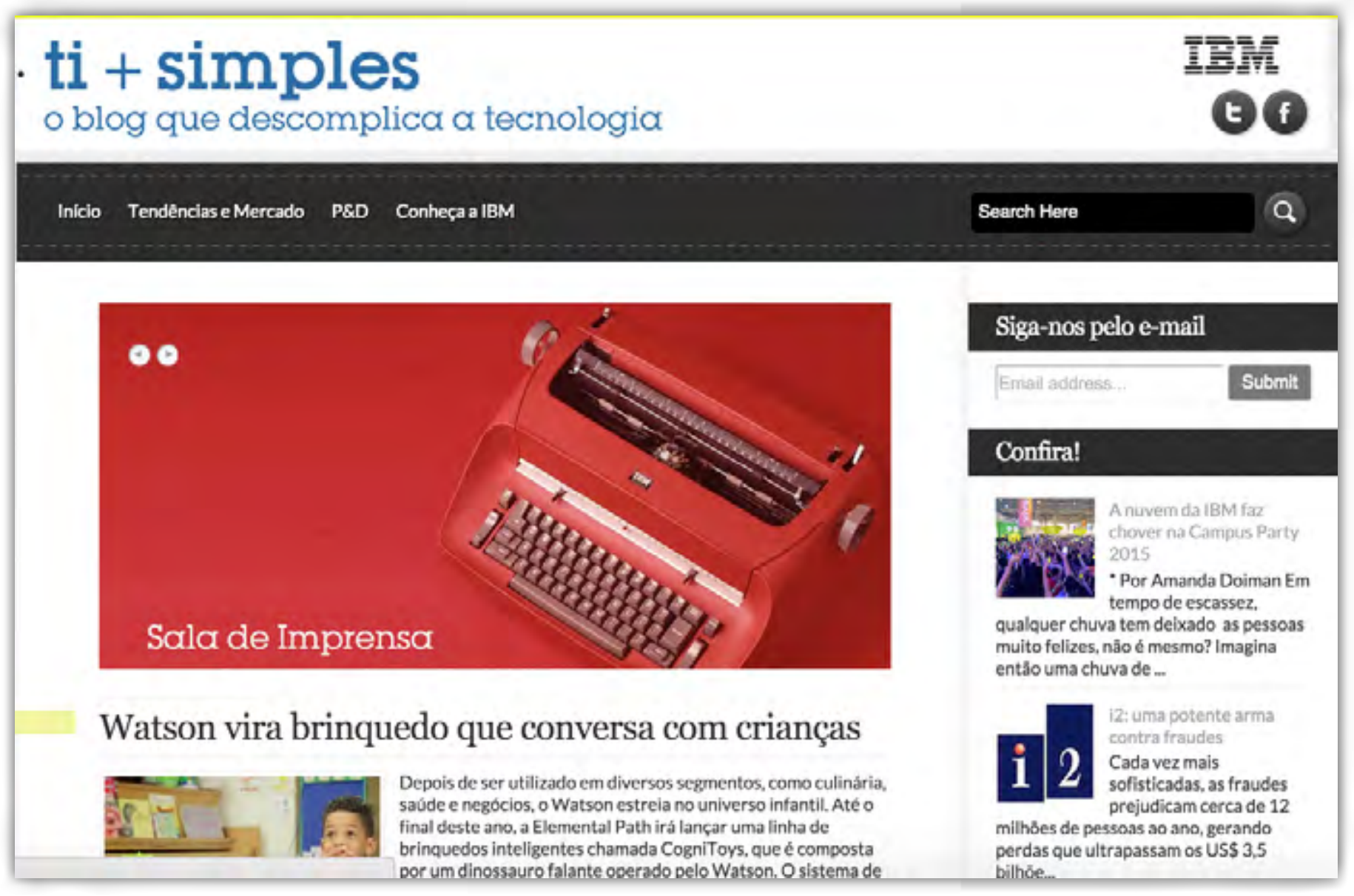

Valendo para ambos os casos, cite-se uma passagem de Eneus Trindade $(2014$, p. 8) que ajuda a justificar as escolhas por dispositivos midiáticos de relacionamento entre as organizações e seus públicos:

A midiatização percebe nessas apropriações do sujeito, uma estrutura que depende de contextos, temporalidades e uma lógica institucional/ideológica que via interações, por meio de dispositivos comunicacionais, modelizam padrões culturais, práticas de sociabilidade, institucionalizam lógicas políticas, crenças e percepções.

Assim, na escolha das organizações por sistemas de mídia elas utilizam hábitos e comportamentos incorporados pelos públicos - no caso os jornalistas (imprensa) - que estão inseridos nesse contexto tecnológico e valem-se de ferramentas de mídias e redes sociais on-line.

\section{Relacionamento com consumidores via uso de influenciadores}

Um formato que costuma atrair audiência para as marcas é o uso de influenciadores on-line como embaixadores. Vemos exemplos desse tipo de relacionamento sobretudo nos mercados de moda, beleza, saúde, bem-estar, fitnesse alimentação. Selecionamos duas influenciadoras on-line que, constantemente, são alvos de ações de marca, seja de maneira paga ou por meio de envio de kits e presentes. 
Figura 3 - Postagem² da blogueira Thassia Neves sobre uma sandália que ganhou de uma estilista de sapatos.

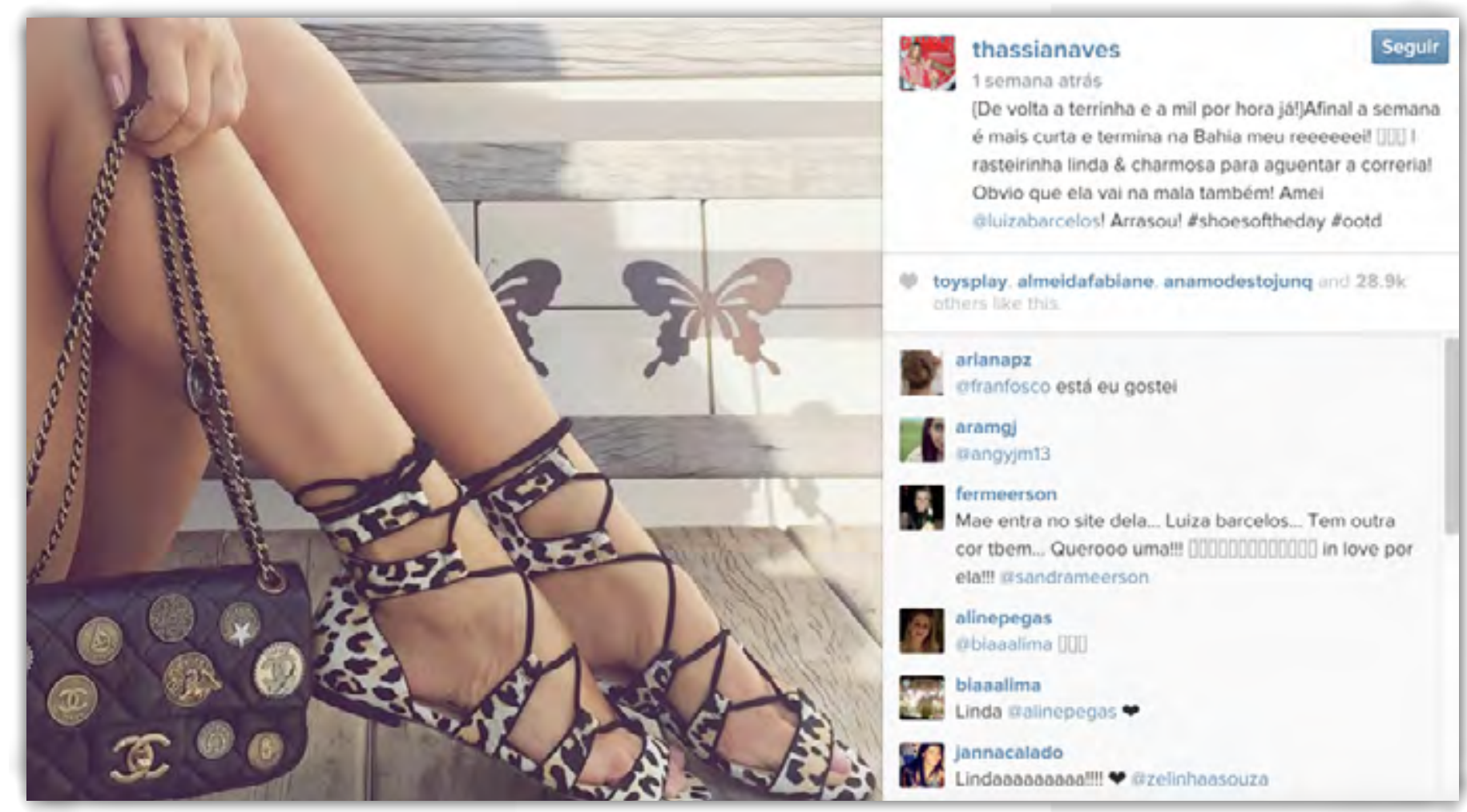

Figura 4 - Postagem ${ }^{3}$ da blogueira fitness Gabriela Pugliesi com os kits para tratamento de cabelo da marca Pantene.

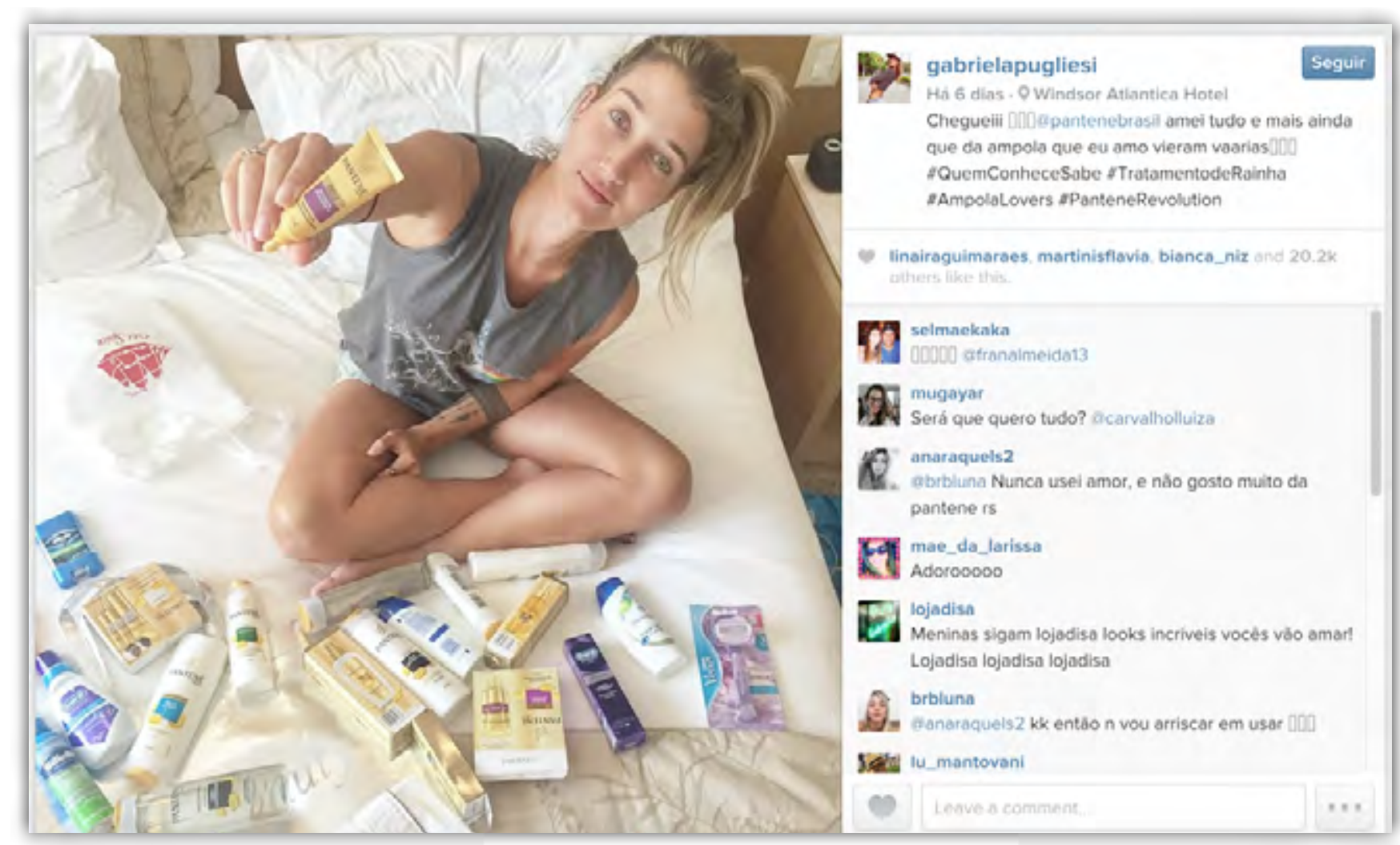

Os influenciadores aglutinam audiências em torno de si e ajudam a construir lembrança de marca, produtos, serviços e campanhas. Tanto os influenciadores quanto as suas audiências querem se envolver com temáticas que sejam úteis, educativas ou inspiradoras. Para isso, as organizações tentam conectar criações de conteúdo com influenciadores on-line que já tenham comunidades engajadas com temáticas parecidas ou afins às suas. 


\section{Relacionamento com clientes - Serviço de atendimento ao consumidor (SAC)}

É sabido que, uma vez presentes na rede, as organizações se veem obrigadas a atender a seus usuários e/ou clientes, seja respondendo às suas dúvidas ou dando encaminhamento aos problemas por eles levantados por meio das plataformas de mídias sociais. Assim, elegemos duas iniciativas de relacionamento com clientes por meio das redes sociais digitais.

O Banco Santander criou um aplicativo (comumente conhecido como app, abreviatura para a palavra em inglês application) de atendimento via Facebook, com o objetivo de minimizar as dúvidas dos seus clientes nessa plataforma. Por meio do app, o cliente digita a sua dúvida e encontra respostas previamente preparadas ou pode se relacionar com um atendente.

Figura 5 - Aplicativo Santander Responde ${ }^{4}$ no Facebook.

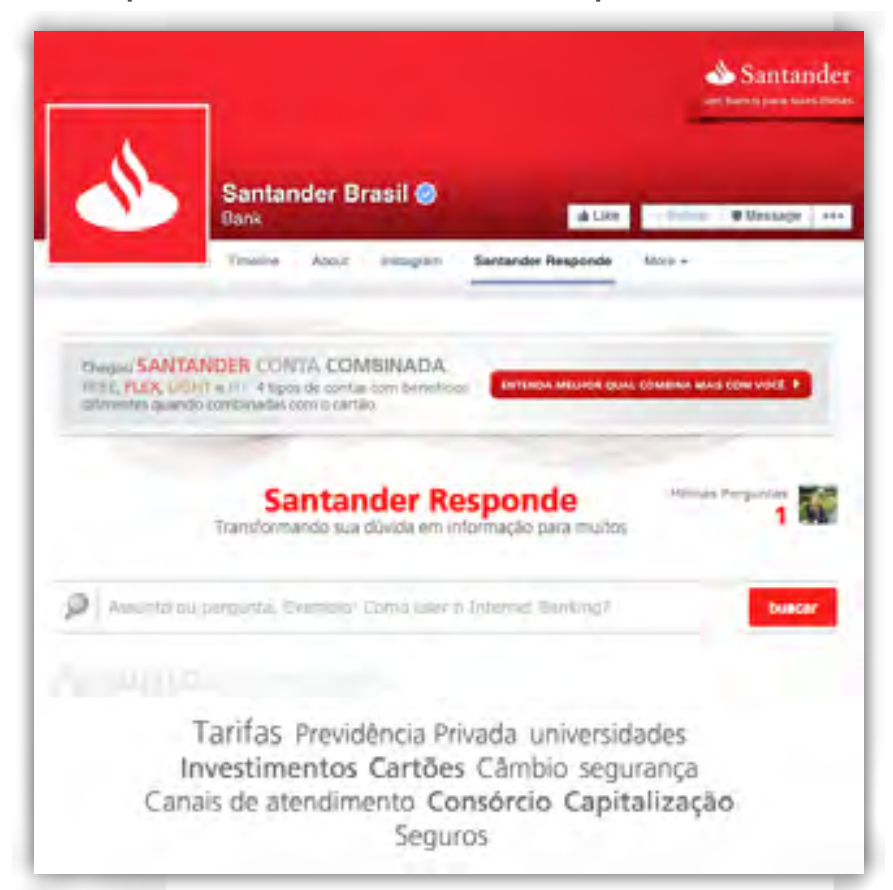

A empresa varejista Ponto Frio é considerada referência de relacionamento nas mídias sociais por utilizar uma linguagem informal e por ser extremamente ágil e assertiva em suas interações. A seguir, exemplo de uma conversa entre uma usuária e o personagem criado especialmente para o Twitter, o Pinguim.

Figura 6 - Interação do Ponto Frio ${ }^{5}$ com uma usuária em seu perfil oficial de Twitter.

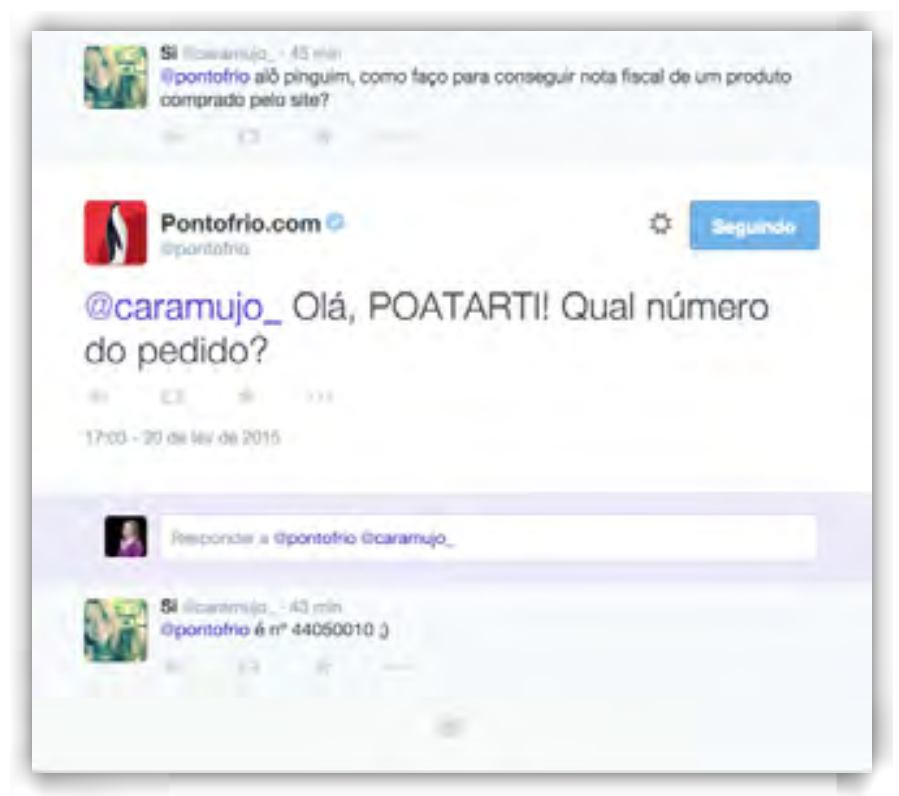

4 Disponível em: <https://www.facebook.com/santanderbrasil/app_225880234096785?app_data=?fb_source=search\&ref=br_tf>. Acesso em 20 fev. 2015.

5 Disponível em: <https://twitter.com/pontofrio/status/568848365989072899>. Acesso em: 20 fev. 20015. 
0 que podemos depreender em ambos os casos citados - Santander Responde e Ponto Frio - é que assistimos a uma complexificação da atividade de relações públicas, oportunizada pelas tecnologias digitais. Daiana Stasiak e Eugenia M. Barichello $(2008$, p. 5) referem-se "à midiatização das relações sociais e às novas formas de relacionamentos instituiçãopúblicos, proporcionadas pelas tecnologias digitais".

\section{Relacionamento com usuários das redes sociais}

\section{por meio de temas ligados à responsabilidade socioambiental}

Algumas organizações optam por aproximar-se dos usuários de mídias sociais por meio de temáticas ligadas ao social ou ao ambiental. É o caso, por exemplo, da Unilever, gigante varejista que usa sua fanpage para explorar temas de responsabilidade social e envolver seus fãs.

Figura 7 - Exemplo de postagem da Unilever ${ }^{6}$ em sua fanpage.

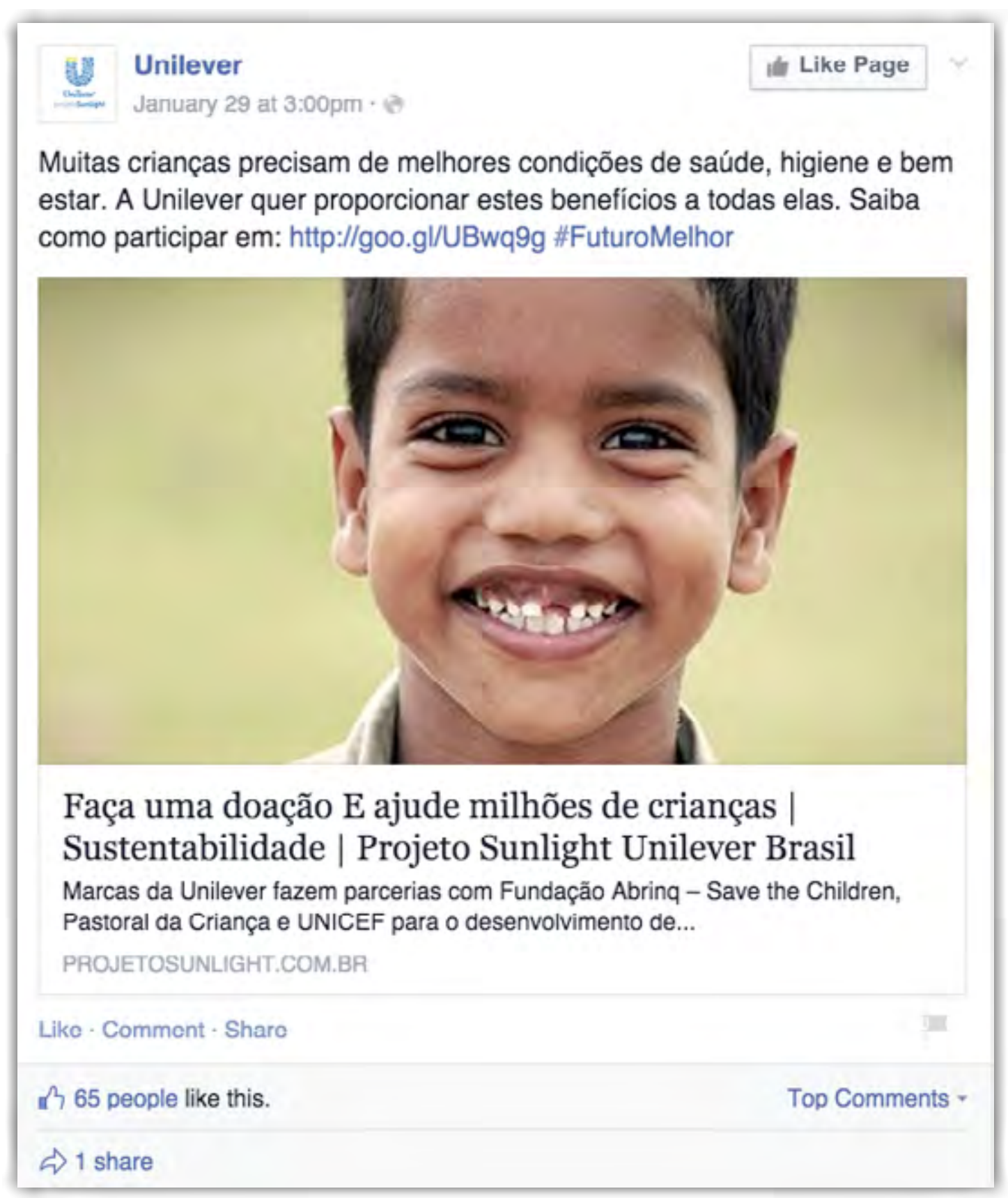

Já a fabricante Tetrapak optou por criar uma plataforma digital para ajudar os consumidores finais a reciclarem suas embalagens e, com isso, contribuírem para o seu descarte correto. 

ESTAMOS FALANDO DA MIDIATIZAÇÃO DAS RELAÇÕES PÚBLICAS?

Figura 8 - Plataforma digital da Tetrapak, Rota da Reciclagem.

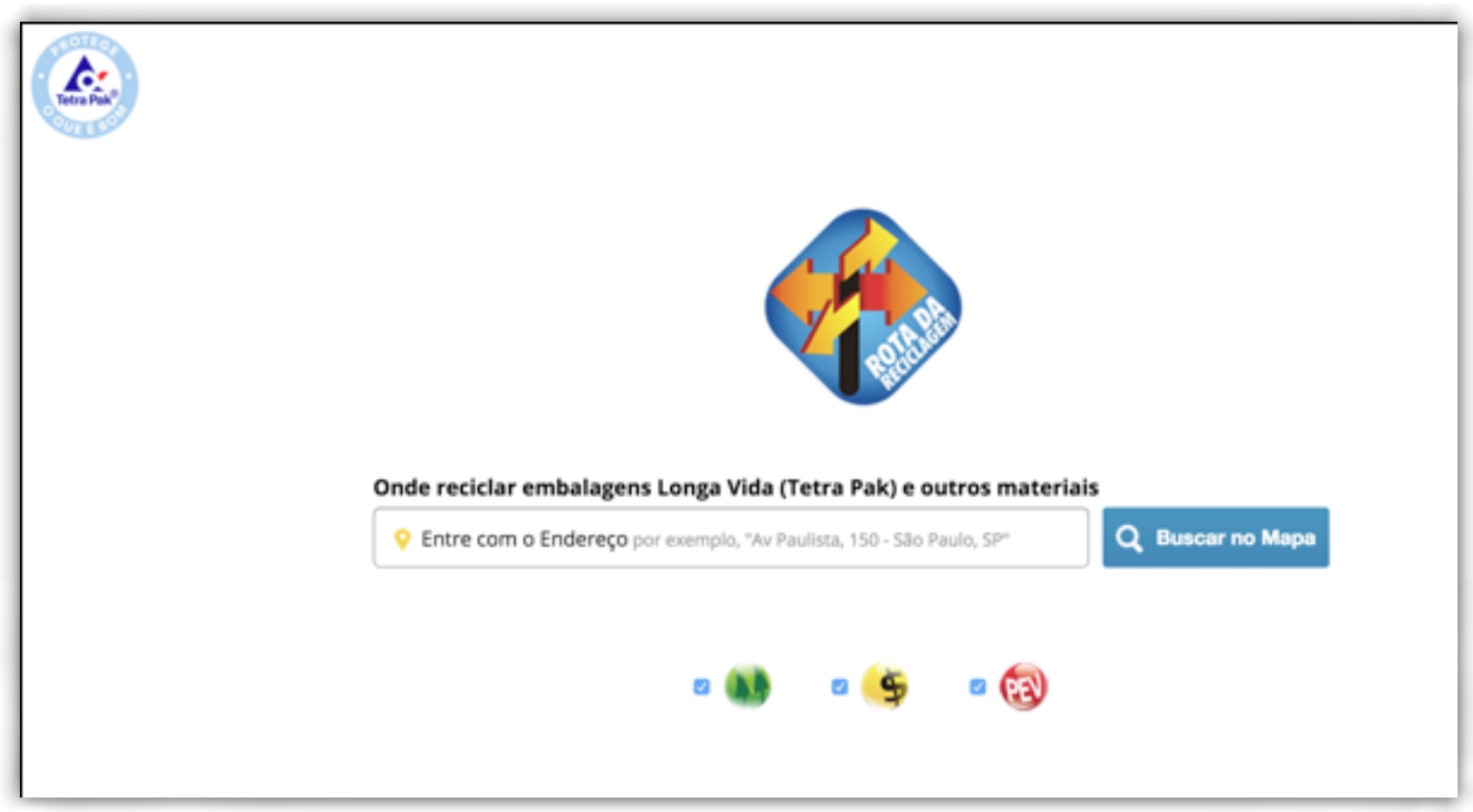

A Fundação Telefônica, braço de responsabilidade social da Telefônica no Brasil, tem entre seus projetos o Voluntariado Digital e incentiva por meio da rede 0 ativismo digital. Trata-se de uma tentativa de relacionamento com públicos ligados à temática do social e do voluntariado que tem sua força e sua mobilização por meio das redes telemáticas digitais.

Figura 9 - Projeto Voluntariado Digital ${ }^{8}$, da Fundação Telefônica.

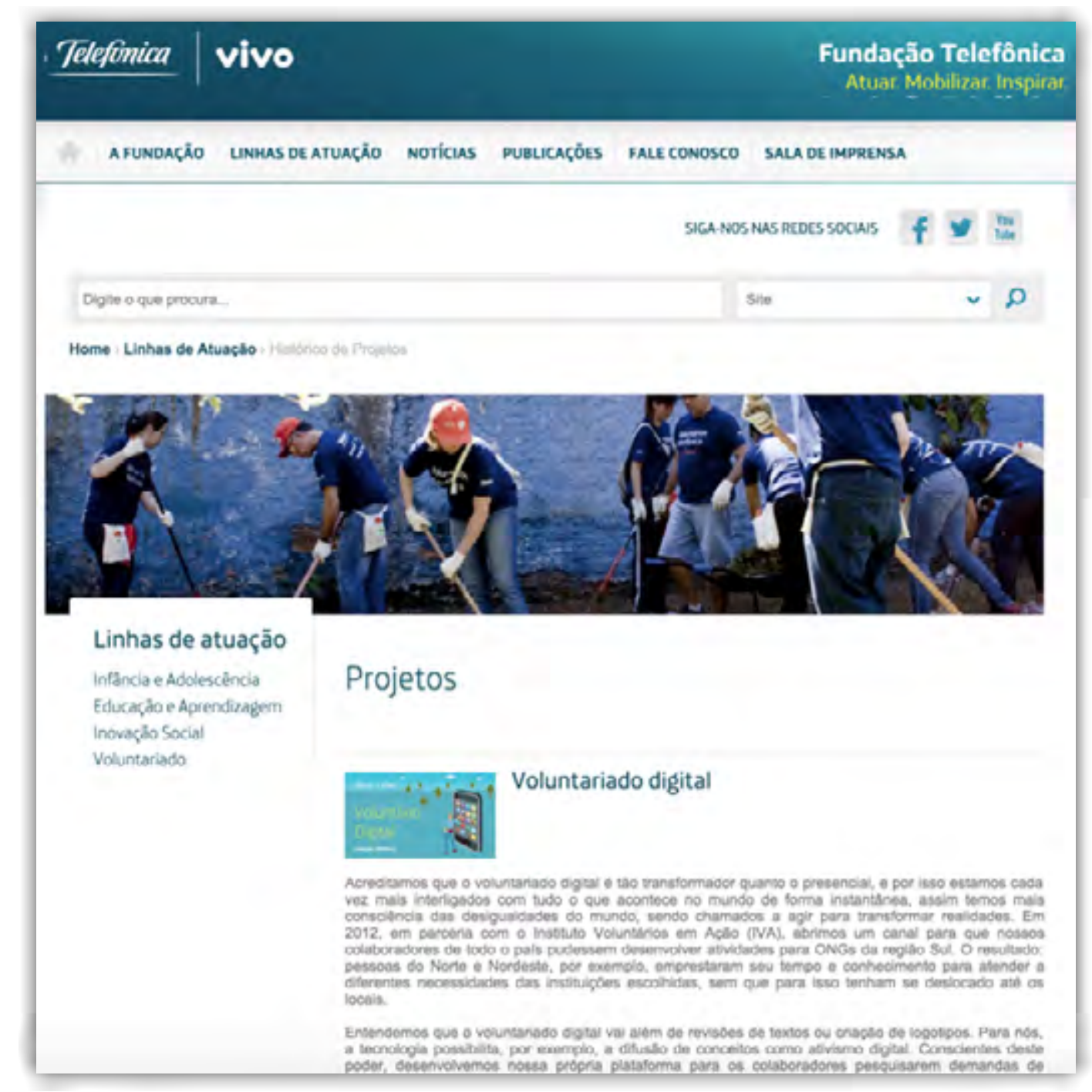

7 Disponível em: <http://www.rotadareciclagem.com.br/index.html>. Acesso em: 20 fev. 2015.

8 Disponível em: <http://www.fundacaotelefonica.org.br/linhas-de-atuacao/historico-de-projetos/Detalhe.aspx?idCategoria=5\&idSubCategoria=11>. Acesso em: 20 fev. 2015. 
Nos dois exemplos ligados ao setor de responsabilidade social corporativa, o que notamos é que, se não fizerem uso das mídias sociais para dar visibilidade à causa e para arrebanhar membros, os projetos podem ser mais difíceis de acontecer, de se promover e de angariar simpatia por parte das audiências.

Portanto, a utilização das mídias sociais em responsabilidade social a serviço do mundo corporativo visa fortalecer 0 relacionamento e o engajamento com os públicos de interesse nas mídias em que estes já estão e participam, e, logicamente, tornar visível a ação da empresa com vistas à divulgação e ao compartilhamento. Sob a perspectiva da ecologia da mídia (Scolari, 2010, apud Carvalho e Barichello, 2013, p. 62), "os meios são as espécies que vivem em um ecossistema e estabelecem relações entre si e com os sujeitos que nele interagem".

\section{CONSIDERAÇÕES FINAIS}

Não se pode generalizar, mas é fato que vivemos a midiatização dos relacionamentos. Não em sua totalidade, mas em boa parte. E tal midiatização das relações entre organizações e usuários levanta a questão de que talvez estejamos mais próximos do modelo simétrico de relações públicas ${ }^{9}$ do que em qualquer outro período que possamos registrar. 0 modelo simétrico, considerado por muitos uma utopia, preconizava a busca de equilíbrio entre os interesses da organização e dos públicos envolvidos.

0 ambiente digital seria o que melhor consegue viabilizar os relacionamentos entre organizações e seus públicos, porque permite diálogo, participação e interações. Assim, é indissolúvel a evolução da tecnologia, ao mesmo tempo em que presenciamos a das relações públicas. As tecnologias da comunicação e da informação estão para as relações públicas assim como as relações públicas estão para a excelência dos relacionamentos entre uma organização e seus públicos.

Bianca Dreyer (2014, p. 68) corrobora o nosso pensamento, confirmando a importância das plataformas digitais para as relações públicas: "[Talvez] o maior ganho para a atividade de relações públicas com a consolidação das tecnologias de comunicação tenha sido a possibilidade de criar outras formas de comunicação que promovam a interação e o diálogo com os públicos".

Barichello et. al. (2013, p. 151) afirmam que há necessidade de nos atualizarmos como profissionais e como área, em função de todo o avanço proporcionado pela digitalização:

O ecossistema midiático contemporâneo demanda atualização das estratégias de relações públicas que visualizem seus públicos como interagentes, que considerem a facilidade ao acesso e o uso real das possibilidades interativas por parte dos participantes da ecologia midiática e o potencial diálogo entre eles. Sob esta perspectiva, não basta estar visível na ecologia midiática, é necessário interagir, ouvir e estabelecer diálogos efetivamente comunicacionais.

Por fim, é possível dizer que evoluímos de Ivy Lee, um dos precursores das relações públicas, à Mark Zuckerberg, fundador do Facebook, que nada tem a ver com a atividade, mas que, por meio de sua plataforma digital, proporciona a nós, profissionais de relações públicas, a chance de dialogarmos e interagirmos melhor, sem intermediários, com os públicos que nos interessam, criando canais, dispositivos, ideias, ambientes que facilitem o acesso destes às organizações de que cuidamos, que gerimos e às quais prestamos serviços.

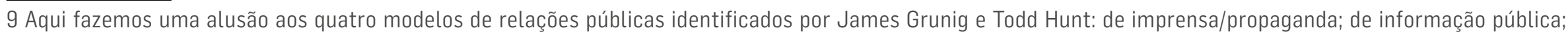

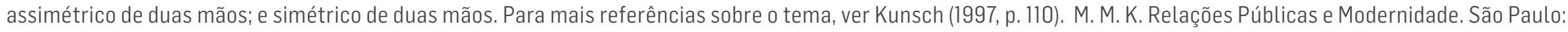
Summus, 1997, p. 110. 


\section{REFERÊNCIAS}

BARICHELLO, E. M. R. et al. Estendendo as práticas de relações públicas sob a perspectiva teórica da ecologia das mídias. In: RUBLESCKI, A.; BARICHELLO, E. M. R. (Org.). Ecologia da mídia. Santa Maria, RS: Facos-UFSM, 2013.

CARVALHO, L. M.; BARICHELLO, E. M. R. Legitimação das organizações midiáticas no ecossistema digital. In: RUBLESCKI, A.; BARICHELLO, E. M. R. (Org.). Ecologia da mídia. Santa Maria, RS: Facos-UFSM, 2013. p. 61-77.

CASTELLS, M. Communication power. Oxford: Oxford University Press, 2009.

CASTRO, G. G. S. Ter clientes é para os fracos: o que importa é ter fãs! São Paulo: ESPM, 2013.

COULDRY, N.; HEPP, A. Conceptualizing mediatization: contexts, traditions, arguments. Communication Theory, n. 23, p. 191-202, 2013.

DREYER, B. M. Relações públicas na gestão das estratégias de comunicação organizacional na sociedade digitalizada: um estudo de caso da Nestlé Brasil S/A. Dissertação (Mestrado em Ciências da Comunicação) - ECA-USP, São Paulo, 2014. Disponível em: <http://www.teses.usp.br/teses/disponiveis/27/27152/tde-13112014-111159/pt-br.php>. Acesso em: 23 fev. 2015.

FAUSTO NETO, A. Fragmentos de uma analítica da midiatização. Revista MATRIZes, v.1, p. 89-105, 2008.

FURTADO, E. J. C. Midiatização e consumo colaborativo no mundo digital: uma articulação de conceitos. In: ENCONTRO DE GTS - COMUNICON, 4ํ, Grupo de Trabalho "Comunicação e consumo: materialidades da cidadania", 08 a 10 de outubro de 2014, São Paulo, ESPM-SP. Disponível em: <www.espm.br/download/Anais_Comunicon.../GTO2_FURTADO.pdf>. Acesso em: 20 fev. 2015.

HEPP, A. As configurações comunicativas de mundos midiatizados: pesquisa da midiatização na era da "mediação de tudo". Revista MATRIZes, ECA-USP, v. 8, n.1, p. 45-64, jan-jul. 2014.

HJARVARD, S. The mediatization of culture and society. London: Routledge, 2013.

KUNSCH, M. M. K. Relações públicas e modernidade: novos paradigmas na comunicação organizacional. São Paulo: Summus, 1997.

LEMOS, A.; LÉVY, P. O futuro da internet. em direção a uma ciberdemocracia planetária. São Paulo: Paulus, 2010.

STASIAK, D.; BARICHELLO, E. M. M. R. WebRP: as estratégias de comunicação de cada tempo. Trabalho apresentado no NP Relações Públicas e Comunicação Organizacional do VIII Nupecom - Encontro dos Núcleos de Pesquisa em Comunicação, evento componente do XXXI Congresso Brasileiro de Ciências da Comunicação. Natal, 2008. Disponível em: http://www. intercom.org.br/papers/ nacionais/2008/resumos/R3-0815-1.pdf. Acesso em 05 mar. 2015.

TERRA, C. F. Mídias sociais...e agora? 0 que você precisa saber para implementar um projeto de mídias sociais. São Caetano do Sul, SP: Difusão; Rio de Janeiro: Editora Senac Rio, 2011.

Relações públicas 2.0: novo campo de atuação para a área. In: CHAMUSCA, M.; CARVALHAL, M. Relações públicas digitais: o pensamento nacional sobre o processo de relações públicas interfaceado pelas tecnologias digitais. Salvador, BA: Edições VNI, 2010b. p. 100-134. 
TRINDADE, E. Mediações e Midiatizações do Consumo. Trabalho apresentado no GP Publicidade e Propaganda, XIV Encontro dos Grupos de Pesquisas em Comunicação, evento componente do XXXVII Congresso Brasileiro de Ciências da Comunicação - Foz do Iguaçu/PR, de 2 a 5/9/2014. Disponível em: http://www.intercom.org.br/ sis/2014/resumos/R9-0253-1.pdf. Acesso em: 20 maio 2015.

Artigo recebido em 27.02.2015 e aprovado em 01.06.2015. 